\title{
Rota de Gramaticalização dos advérbios ainda e sempre
}

Beatriz Del Grossi Ferreira ${ }^{2}$

RESUMO: Este artigo apresenta uma possível rota de gramaticalização para os itens ainda e sempre, tradicionalmente classificados como advérbios de tempo. Fazendo incursões nos dados de língua falada, percebemos que os itens passam a assumir domínios funcionais mais amplos. Esse deslizamento funcional, também chamado de gramaticalização, é um processo que parte do léxico em direção à gramática, contribuindo para entender as novas formas que surgem na língua. O presente trabalho é resultado da pesquisa de iniciação científica, que tem como amostra dados de língua falada, extraídos das 340 horas de gravações com falantes cultos, na década de 70 pelos pesquisadores do projeto NURC-SP.

Palavras-chave: advérbio, ainda, sempre, gramaticalização.

\begin{abstract}
This paper presents a possible route for the grammaticalization of items ainda (still) and sempre (always), traditionally classified as adverbs of time in Portuguese language. We study how that items start their grammaticalization process. What we know is the unidirectionality of this change move these lexical items to a grammatical items. The sample of spoken language was extracted from 340 hours of recordings with speakers of standard Portuguese in the $70 \mathrm{~s}$ by researchers on the project NURC-SP.
\end{abstract}

Keywords: Adverb, yet, always, grammaticalization.

\section{Introdução}

teoria da gramaticalização insere-se no âmbito da linguística histórica, numa perspectiva funcionalista da linguagem. Ao contrário do polo formalista, que ressalta a forma linguística, ficando sua função

\section{(FFLCH-USP-FAPESP).}

2 Agradeço ao parecerista ad hoc que avaliou criticamente meu texto. Todas as imperfeições que restarem são de minha inteira responsabilidade. 
no plano secundário, o polo funcionalista defende que o falante, o interlocutor e o contexto da conversa desempenham papel predominante. Assim, a língua é vista como um instrumento de comunicação que, como tal, não pode ser analisada como um objeto autônomo, mas como uma estrutura maleável, sujeita a pressões oriundas de diferentes situações comunicativas, que ajudam a determinar sua estrutura gramatical (Cunha, 2003).

Alguns vieses funcionalistas ganham força nos Estados Unidos na década de 70, com Sandra Thompson, Paul Hopper e Talmy Givón, que defendem uma linguística baseada no uso, cuja tendência principal é observar a língua do ponto de vista do contexto linguístico e da situação extralinguística. A sintaxe é uma estrutura em constante mutação em consequência das vicissitudes do discurso.

O conceito de "gramática emergente" é explicitado de forma marcada numa associação com o nome do linguista Hopper $(1987,1991)$, pois o autor assume que a gramática de uma língua nunca está completa. A estabilidade é relativa e aparente: o que foi sistematizado entra em processo de desgaste gramatical (restrição de ocorrência/esvaziamento semântico), indo, portanto, do gramatical para o não gramatical (discursivização). Esse processo de mudança linguística é conhecido por gramaticalização, visto como um processo que transforma gradualmente um item lexical em item de sentido gramatical ou, ainda, um item/construção gramatical em um item/construção mais gramatical ainda. Assim, novas funções/valores/usos estão constantemente surgindo, mobilizando, para esse processo, formas já existentes (Gonçalves, Lima-Hernandes e Casseb-Galvão, 2007; Heine, Claudi \& Hünnemeyer, 1991).

A noção de mudança linguística, juntamente às propostas de gramaticalização do início da década de 90, é associada à unidirecionalidade e sucessividade, caracterizando-se por uma evolução linear, segundo a qual um valor implica sempre a existência de um valor anterior. Esses princípios, contudo, serão questionados nesta proposta de análise de gramaticalização dos elementos ainda e sempre.

No ponto extremo do contínuo de mudança, localiza-se o processo de discursivização, que focaliza a trajetória de retorno dos elementos da gramática ao discurso. Para Traugott e König (1991) importa a pressão de informatividade, já que por convencionalização de implicaturas conversacionais o elemento linguístico passa a assumir um valor novo. Assim, a mudança linguística deve ser entendida como um fenômeno tridimensional, ou seja, a trajetória de mudança 
de um elemento linguístico é um reflexo de, pelo menos, três aspectos diferentes: tempo, cognição (língua humana como reflexo do comportamento) e uso.

Esse processo dinâmico pode ser apreendido a partir dos padrões fluidos da linguagem por meio do reconhecimento dos graus variados de gramaticalização de itens-fonte. Nessa proposta, os itens-fontes são os elementos ainda e sempre, que assumem novas funções/valores/usos se observadas numa abordagem diacrônica. Numa abordagem sincrônica, a apreensão desses deslizamentos funcionais torna-se tarefa mais árdua, posto que não há um tempo considerável que favoreça essa análise. Então, torna-se necessária a adoção de um modelo de análise que permita a identificação da mudança, ainda em seus tenros estágios.

Segundo Coutinho (1962), os advérbios portugueses derivam-se do latim. A língua vulgar latina costumava frequentemente formar locuções com valor adverbial, como em ainda: inde + ad ou binc $+d e+a d>$ inda; $a d+d e+b i n c+a d$ ou $a d+i n d e+a d>i n d a+a>$ ainda. Já a sua etimologia é incerta, "de origem até hoje não explicada satisfatoriamente" e suas fontes históricas remetem aos séculos XIII ainda, XIII ajnda e XIII aynda (Houaiss e Villar, 2001: 128). Para Antonio Geraldo da Cunha (1982: 24), ainda "provavelmente da combinação dos vocábulos latinos $a d+i n d e+a d$, ou da variante antiga inda com o prefixo A-. Suas fontes históricas seriam o século XIII aynda, XIII einde e XIII inda".

De acordo está Corominas (1991:89) quando diz que ainda 'aun, todavia', é uma herança recebida do galego-português:

advérbio gallego-portugues de etimologia incierta; probablemente es de origen prerromano, y afín a la conjunción indi o inda, que com el valor de 'y' es frecuente em las inscripciones sorotápticas de época imperial, encontradas em el Poniente y el Oriente de la Península; es verosímil que sea uma variante de esta misma palabra, que significando primero 'todavia', 'y también', pudo llegar a funcionar como uma mera copulativa. Primeira documentação: inda y ainda, ya frecuentes em cantigas gallegas desde século XIII.

A etimologia da palavra sempre remete a semper (Coutinho, 1962), que aparece no português tanto como advérbio como "um elemento complementar antepositivo, de formação vernácula do latim semper", que significava "de uma 
vez por todas, sempre", ocorrendo em sempre e em compostos, oriundos da área da botânica: sempre-em-pé, sempre-liso, sempre-lustrosa, sempre-noiva, sempre-noiva-dos-modernos, sempre-verde, sempre viçosa, sempre-viva, sempre-viva-da-serra, sempre-viva-do-mato, sempre-vivense, sempre-vivo, sempre-viva-vermelho. Para tais definições a fonte histórica refere-se aos séculos XIII sempre, XIII senpre, XIV ssepre. (Houaiss, 2001: 2544). Na Gramática do latim vulgar, Maurer (1959: 43) menciona os desdobramentos de semper: português sempre, espanhol siempre, catalão sempre, provençal sempre $(s)=$ já , italiano e logudorês sempre ${ }^{3}$. Para Coutinho (1962: 313), sempre provém da forma semper.

\section{Padrões funcionais e gramaticalização em processo}

Partindo da noção de padrão funcional, tal como assumido por Lima-Hernandes (2005), identificamos alguns padrões funcionais, isto é, delimitamos graus variados de gramaticalização dos itens-fontes ainda e sempre. Para o item ainda foram identificados oito padrões após minuciosa verificação e para o item sempre, apenas três. Analisaremos os itens separadamente, que serão classificados através de seus padrões funcionais.

a) padrões funcionais do item ainda

Ainda 1: Detém um caráter adverbial de tempo que se inicia no passado e termina num tempo também passado, enfatizando a continuação dessa ação pretérita. Admite as paráfrases até então, até aquele momento, recentemente. Toma por escopo a oração, mas também pode tomar como escopo apenas o verbo. Invariavelmente vem sucedido por um advérbio, mas pode vir intercalado numa locução verbal. Nota-se que, na maioria dos exemplos, esse padrão vem acompanhado de palavra ou locução temporal (sublinhado), reiterando a ação pretérita.

Esse termo tem, segundo Maurer Jr. (1959:43) a seguinte rota: em Corominas (1991: 240) há informação sobre o uso generalizado no espanhol: "de uso general em todas las épocas y conservado em todos los romances de Occidente". Além de siempreviva, Corominas cita ainda sempiterno, tomado de sempiternus. 
(1) ... as notícias mais imediatas que vêm pelas agências então sabe-se lá outro dia ainda vi no Jornal da Globo... os movimentos da China Celestial de adeptos das doutrinas e de pessoas divergentes... mas o que se passa no Amazonas... (NURC, p.258)

Ainda 2: Detém um caráter adverbial de tempo que se inicia no passado e vai até o presente, apesar de o verbo da oração estar no tempo presente. Admite as paráfrases até agora, até o presente. Usado para dar continuidade à ação, seu escopo é a oração ou o sintagma verbal.

(2) ... nós estamos com o metrô muito...sei lá...a gente está acostumado já de ouvir falar de metrô porque está muito mas... não não temos metrô ainda metrô tem que ser uma malha... certo? nós temos uma linha...coitadinha não sei se dá para chamar ela de metrô... (NURC, p. 27)

Ainda 3: Sinaliza a possibilidade de realização futura de um evento. Detém um caráter de indefinidor temporal cujo escopo é uma oração. Como é um julgamento do falante, encaixa-se na categoria qualidade de Heine, Claudi de Hünnemeyer (1991), como se fosse um epistêmico. Admite as paráfrases "seguramente", "tenho certez̧a". Não há diferença quanto ao tipo de verbo, prevalecendo o transitivo.

(3) ... mudava...eu era das tais que mudava com água oxigenada... uma hora eu estava loira...com água oxigenada...outra hora então diziam "você na sua vaidade você ainda vai se prejudicar” ... ficava loira... nuns tempos que enjoava do loiro e pegava a negrita lembra? (NURC, p. 231)

Ainda 4: Sinaliza a adição de um tópico em uma discussão. Detém um caráter aditivo, atuando como marcador de inclusão tópica, cuja estrutura é oração + ainda + oração. Admite as paráfrases também, mais. Seu escopo é a oração.

... estava ainda conversando como uma pessoa ontem aqui que dizia né? Que ele é muito ocupado trabalhava o dia inteiro estudava à noite fazia o curso... 
e ainda no fim de semana ia para Minas Gerais fazer o curso de Advocacia... (NURC, p. 90)

Ainda 5: Detém um caráter pragmático, marcando a duração do tópico desde o passado ao presente. É um sinalizador ao interlocutor. ...não ele teve escritório no início da carreira...teve escritório durante...oito anos mais ou menos...depois...ainda com escritório... e como ele tinha liberdade de advogar ele também ... exercia a advocacia do estado né? e depois que ele começou a lecionar quando houve a necessidade do regime de dedicação... (NURC, p. 165)

Ainda 6: É o ainda que. Sinaliza concessão, além de ligar orações/idéias. Seu escopo é uma oração e admite as paráfrases apesar de, mesmo que. Sua relevância é sintática posto que sofre decategorização de advérbio > conjunção. ... o nome de propriedade era o nome do antigo proprietário... então nessas condições havia que se mudar o nome...meu sogro foi imediatamente chamado para residir como primeiro morador ainda que nós tivéssemos condições de pagar um caseiro que lá existia mas o sogro estava... estabelecido num sítio... (NURC, p. 108)

Ainda 7: Comporta-se como um intensificador que ocupa sintaticamente a posição posposta ao seu escopo, que é um modificador de verbo ou um modificador de nome Por isso invariavelmente vem precedido por um adjetivo ou advérbio (sublinhado). Admite a paráfrase muito.

(7) ... bom eu sou universitário agora...agora já não está adiantando mais você tem que fazer uma pós para ascender mais ainda mas isso... é uma hierarquia não deixa de ser né? ... (NURC, p. 47)

Ainda 8: Sinaliza idéia de contraposição, atuando como uma partícula contrastiva de reforço. Sua paráfrase é mesmo, mesmo assim, mas. 
(8) ... bom eu gosto muito de Veja... ou da revista Veja... eu sou assinante ... eu sou leitor sistemático... acredito que quando leio pouco leio setenta e cinco por cento portanto três quartos do conteúdo da revista...mesmo de assuntos que aparentemente eu não leio nos jornais...são determinadas partes que afastam-se assim daquele meu ramo de interesse mas ainda assim acabo lendo no Veja... (NURC, p. 126)

b) padrões funcionais do item sempre

Sempre 1: Sinaliza uma ação codificada por verbo transitivo ou intransitivo em tempo presente, passado ou futuro, indicando a totalidade do tempo. Esse item admite as paráfrases constantemente, continuamente e toma por escopo o sintagma verbal. Há a repetição da ação no tempo; independente do que ocorra, o resultado será o mesmo. De acordo com Negrão (2002) o padrão de comportamento ocorre quando sempre está em posição pós-verbal, o que foi confirmado em todos os exemplos.

(9) ... só que eu de certa forma me habituei a ler no ônibus... então eu levava um livro um jornal e era uma hora de leitura né? eu conseguia sempre...pelos horários que eu me servia da condução não encontrava grande dificuldade... (NURC, p. 105)

Sempre 2: Sinaliza ações no passado e no presente. Há a repetição de evento condicionado à ocorrência de outro evento (correlação de eventos). Esse item tem por escopo uma oração. Admite as paráfrases muito frequentemente, geralmente, babitualmente.

... você ouve aí o homem do tempo...fala isso aquilo...não deu nada daquilo ele chega à noite e fala não sei o que e deu bateu voltou não vem nada daquilo então ele sempre se desculpa entende? (NURC, p. 63)

Sempre 3: São os padrões nem sempre ou quase sempre. Sinaliza uma ação tanto no presente quanto no passado, admitindo a paráfrase na maioria das vezes, quando 
se tratar de quase sempre ou a paráfrase algumas vezes, quando se tratar de nem sempre. O escopo é variável, podendo ser uma oração ou um sintagma menor.

...nesse aspecto a televisão está prestando um grande desserviço...sem considerar... a mensagem quase sempre de violência que ela leva... e junto com esta mensagem de violência... (NURC, p. 114)

... porque todo mundo tem algum amigo... que precisa que é uma pessoa ótima... que tem muita experiência... que não se que...que tem mil e um curso tudo isso né?... e nem sempre... algumas vezes consegue...mas depende sempre mais do cliente do que do candidato né? (NURC, p.165)

Após a identificação desses padrões, verificamos a pertinência da sequência proposta na escala de abstratização metafórica por Heine, Claudi \& Hünnemeyer (1991), qual seja, pessoa $>$ objeto $>$ atividade $>$ espaço $>$ tempo $>$ qualidade. Os autores defendem a unidirecionalidade como atrelada categoricamente ao processo de gramaticalização, que seria resultante de uma criatividade individual, influenciada por estratégias universais de manipulação.

Assim, a criatividade do falante é vista como a habilidade de pensar o velho de uma nova forma, trazendo movimentações que ocorrem entre os usos/ acepções de uma mesma palavra. Essas movimentações não necessariamente precisam culminar com a constituição de uma nova categoria, mas já pode ser reconhecida com a simples alteração de algum traço menos perceptível ao falante comum.

No processo de mobilização de velhas formas para novas funções, atuam dois mecanismos: a metáfora e a metonímia. O primeiro indica que um esvaziamento do índice lexical é um indício de gramaticalização e o segundo revela uma motivação pragmática, que envolve a reinterpretação induzida pelo contexto. Dessa forma, metáfora e metonímia constituiriam processos complementares. É por meio da ordenação de categorias conceptuais que se pode observar o processo de abstratização, sendo que a hierarquia e a unidirecionalidade implicam que as mudanças são operadas sempre da esquerda para a direita, isto é, de categorias cognitivas mais próximas do indivíduo (portanto, mais concretas) para categorias cognitivas mais distantes do indivíduo (menos concretas). Assim, o item ainda classificado normativamente como advérbio 
de tempo passa a representar outros conceitos mais abstratos. É nesse sentido que proponho uma possível rota de gramaticalização para o item ainda:

\begin{tabular}{|c|c|c|c|}
\hline GRAMATICAL & \multicolumn{2}{|c|}{ TEXTUAL } & EPISTÊMICO \\
\hline $\begin{array}{lc}\text { duração } \rightarrow & \begin{array}{c}\text { duração } \\
\text { (tempo) }\end{array} \\
\text { (assunto) } \\
\text { a. } 1 \rightarrow \text { a. } 2 & \text { a. } 5\end{array}$ & $\begin{array}{l}\rightarrow \text { partícula contrastiva } \\
\text { de reforço } \\
\text { a. } \quad 8 \\
\rightarrow \text { adição de } \\
\text { informação } \\
\text { a. } 4\end{array}$ & $\begin{array}{c}\rightarrow \text { concessivo } \\
\text { a. } 6 \\
\rightarrow \text { intensificador } \\
\text { a. } 7\end{array}$ & $\begin{array}{l}\rightarrow \quad \text { a. } 3: \\
\text { julgamento, } \\
\text { qualidade. }\end{array}$ \\
\hline
\end{tabular}

O que o esquema apresenta potencialmente suscita o questionamento, na verdade, da hipótese da unidirecionalidade. Tentando aplicar uma escala direcional, inserimos o elemento protótipo como o ainda 1 (a. 1, na tabela), já que possui um aspecto de tempo durativo. Contudo, ele inicia-se no passado e termina também num passado, originando o ainda 2 (a. 2), também detentor de aspecto temporal, mas agora com ações que começam num passado próximo e terminam num tempo presente. Dessa duração temporal, passa à duração do assunto, caracterizado pelo ainda 5, detentor de um caráter pragmático, marcando a duração do tópico desde o passado ao presente. Como é um sinalizador ao interlocutor, representa uma linha tênue aqui separando os domínios da gramática e do texto. Partindo da duração do assunto, apresentam-se dois outros caminhos: contrapor ideias ou simplesmente adicioná-las. É o que mostram, respectivamente, o ainda 8 (a. 8), chamado na tabela de partícula contrastiva de reforço e o ainda 4 (a.4), denominado adição de informação, já que sinaliza a adição de um tópico em uma discussão. Da partícula contrastiva de reforço origina-se o ainda 6, denominado ainda concessivo (a. 6, é o ainda que), que atua no domínio do texto, já que liga orações. Por outro lado, da adição de informação, emerge o ainda 7 (a. 7), denominado ainda intensificador, visto que intensifica a ideia do falante. O padrão, contudo, mais gramaticalizado, é o ainda 3 (a. 3), caracterizado como julgamento, qualidade. Apesar de não ser possível, com essa rota, pontuar sua origem, sabe-se que é ele que entra mais a fundo na categoria qualidade, na escala de abstratização metafórica de Heine (1991). Deixa, assim, 
a sua categoria cognitiva básica, que é o tempo, para comportar-se como um epistêmico, já que é indício de julgamento do falante.

Já a rota de gramaticalização para o item sempre é bem mais simples:

$$
\begin{array}{cc}
\text { Repetição de ação } \rightarrow \text { repetição de evento condicionado } & \rightarrow \text { quase sempre, s.3 } \\
\text { s.1 } & \rightarrow \text { nem sempre, s.3 } \\
& \text { s.2 }
\end{array}
$$

O que encontramos foi justamente a marcação de usos/funções que identificam este elemento como aspecto durativo, não se gramaticalizando totalmente a ponto de mudar de categoria ou passar a outros domínios. A rota começa com o elemento sempre 1 (s.1), que designa repetição de ação na totalidade do tempo, abarcando passado, presente e futuro. É o elemento protótipo, que dará origem ao sempre 2 (s.2), que designa também repetição de um evento, mas relacionado à ocorrência de outro evento, indicando assim uma correlação de eventos, em tempo passado e presente. Dessa correlação de eventos origina-se o sempre 3 (s.3), que designa a frequência com que o evento ocorre. Assim, temos um evento que pode ser realizado na maioria das vezes, o que indica a locução quase sempre ou que um evento pode ser realizado algumas vežes, o que indica a locução nem sempre. Reitero, aqui, a surpresa em ver que o elemento sempre permanece em seu aspecto durativo inalterável desde o seu surgimento, no latim semper, até os dias de hoje.

\section{Considerações finais}

Retomemos a proposta para a linha de abstratização de Heine, Claudi \& Hünnemeyer (1991), a qual inclui as seguintes categorias: pessoa $>$ objeto $>$ atividade $>$ espaço $>$ tempo $>$ qualidade. Lima-Hernandes (2006), em seu estudo sobre as rotas de gramaticalização das estruturas $x$-que, assumindo a unidirecionalidade, sugere que esse continuum deva ser revisto a depender do fenômeno sob análise. Foi contribuição dessa pesquisa a revisão da ordem da categoria processo como derivada de espaço e tempo. O que Lima-Hernandes têm proposto é que outras categorias podem emergir nessa linha de abstratiza- 
ção a depender do fenômeno investigado. A linha desenvolvida com base em resultado de análise de estruturas $x$-que é a seguinte: corpo $>$ pessoa $>$ objeto $>$ instrumento $>$ espaço $>$ tempo $>$ processo $>$ qualidade. Como resultado da pesquisa em questão, acreditamos que o item ainda se encaixa nesse novo continuum, já que parte da esfera gramatical (o tempo é a sua categoria cognitiva básica), passa para a esfera textual para enfim comportar-se como um epistêmico, entrando na categoria qualidade. Dessa forma, podemos destacar que a esfera textual se inclui na categoria processo da escala de abstratização, o que confirma a existência desse novo continuum. Já o item sempre não pode encaixar-se da mesma forma que o item ainda, visto que encontramos apenas a marcação de usos/funções que identificam este elemento com o aspecto durativo (processo), não se gramaticalizando totalmente a ponto de mudar de categoria cognitiva básica, o tempo, não abarcando a nova categoria qualidade.

A despeito de os desenvolvimentos revelarem-se multilineares, em nenhum momento rompem com o princípio fundamental dos desenvolvimentos por gramaticalização: a unidirecionalidade, que é referendada na rota de desenvolvimento das categorias cognitivas, tornando usos mais concretos em mais abstratos continuamente.

\section{Referências Bibliográficas}

COROMINAS, J e PASCUAL, J.A. (1991). Diccionario crítico etimológico castellano e hispánico, vol. I e vol. V. Madrid: Gredos.

COUTINHO, Ismael de Lima. (1962) Gramática Histórica. Rio de Janeiro: Acadêmica. CUNHA, Antonio Geraldo da. (1982). Dicionário etimológico Nova Fronteira da língua portuguesa. Rio de Janeiro: Nova Fronteira.

CUNHA, Maria Angélica Furtado da, MARTELOTTA, Mário Eduardo e OLIVEIRA, Mariângela Rios de. (2003). Linguistica funcional - teoria e prática. Rio de Janeiro: DP \& A.

GONÇALVES, Sebastião Carlos Leite; LIMA-HERNANDES, Maria Célia; CASSEBGALVÃO, Vânia Cristina. (2007). Introdução à gramaticalização. São Paulo: Parábola,.

HEINE, Bernd; CLAUDI, Ulrike \& HÜNNEMEYER, Friederike. (1991b). Grammaticalization: a conceptual framework. Chicago e London: The University of Chicago Press. HOPPER, Paul. (1991). On some principles of grammaticalization. In: TRAUGOTT, E.C. \& HEINE, B. (eds). Approaches to grammaticalization. Amsterdam: John Benjamins, pp.17-35. 
516 Beatriz Del Grossi Ferreira

HOUAISS, Antônio \& VILLAR, Mauro de Salles. (2001). Dicionário Houaiss da lingua portuguesa. Rio de Janeiro: Objetiva.

LIMA-HERNANDES, Maria Célia. (2005). A interface sociolinguistica/gramaticalização: estratificação de usos de tipo, feito, igual e como. Tese de doutoramento. Campinas: IEL/ Unicamp.

MAURER, Theodoro Henrique Junior. (1959). Gramática do latim vulgar. Rio de Janeiro: livraria acadêmica.

Recebido em: 27/11/2010

Aprovado em: 04/05/2011 